\title{
Open Perineal Dislocation of the Hip With Fracture of the Femoral Head and Greater Trochanter: A Case Report
}

\author{
Alireza Jalili ${ }^{1,} ;$ Mohammad Zarei $^{1}$ \\ ${ }^{1}$ Department of Orthopedic Surgery, Hormozgan University of Medical Sciences, Bandar Abbas, IR Iran \\ ${ }^{*}$ Corresponding author: Alireza Jalili, Department of Orthopedic Surgery, Hormozgan University of Medical Sciences, Bandar Abbas, IR Iran. Tel: +98-9151132183, Fax: +98-7633345003, \\ E-mail: alirezajalili.jalili@gmail.com
}

Received: September 12, 2014; Revised: February 21, 2015; Accepted: February 28, 2015

\begin{abstract}
Introduction: Traumati c anterior dislocation of the hip is not common and open perineal variant of the inferior type of anterior dislocation is an even rare event.

Case Presentation: We report a case of open perineal variant of the inferior type of anterior hip dislocation, with concomitant fracture of the femoral head and greater trochanter, in a 17-year-old male patient. Closed reduction of dislocation and later open reduction and fixation of the greater trochanter were performed. Eighteen months after the injury, the femoral head resorption, due to infection and avascular necrosis, led to a poor functional outcome.

Conclusions: Open perineal variant of anterior hip dislocation can lead to very poor outcome when performed with closed reduction.
\end{abstract}

Keywords: Hip dislocation; Femur head; Fracture

\section{Introduction}

The hip is a ball-and- socket joint, in which the femoral head is covered by the bony acetabulum. Strong capsulo-ligamentous structures, such as the iliofemoral ligament, anteriorly, and the ischiofemoral ligament and short external rotators, posteriorly, resist hip dislocation forces and a significant force is required to disrupt this robust capsulo-ligamentous structure of the most stable joint in the body (1). Anterior hip dislocation is uncommon and constitutes only $10-15 \%$ of all hip dislocations $(1,2)$. Traumatic open anterior perineal hip dislocation with concomitant femoral head fracture is a very rare event (3-6). The present case discusses the causes of its poor prognosis.

\section{Case Presentation}

Our patient was a 17-year-old male brought to our hospital after a motorcycle accident, with left lower limb deformity. In physical examination there were abdominal tenderness, left hip flexion, abduction and external rotation deformity, swelling and deformity of left leg. Left leg pulses were not detectable and there were weak toe flexor and absent toe extensor, and hypoesthesia of left foot. Capillary refill time was 4 seconds. The femoral head was broken and extruded near the anus (Figure 1). Radiography showed perineal dislocation of the left hip, tibia and fibula fracture (Figure 2).

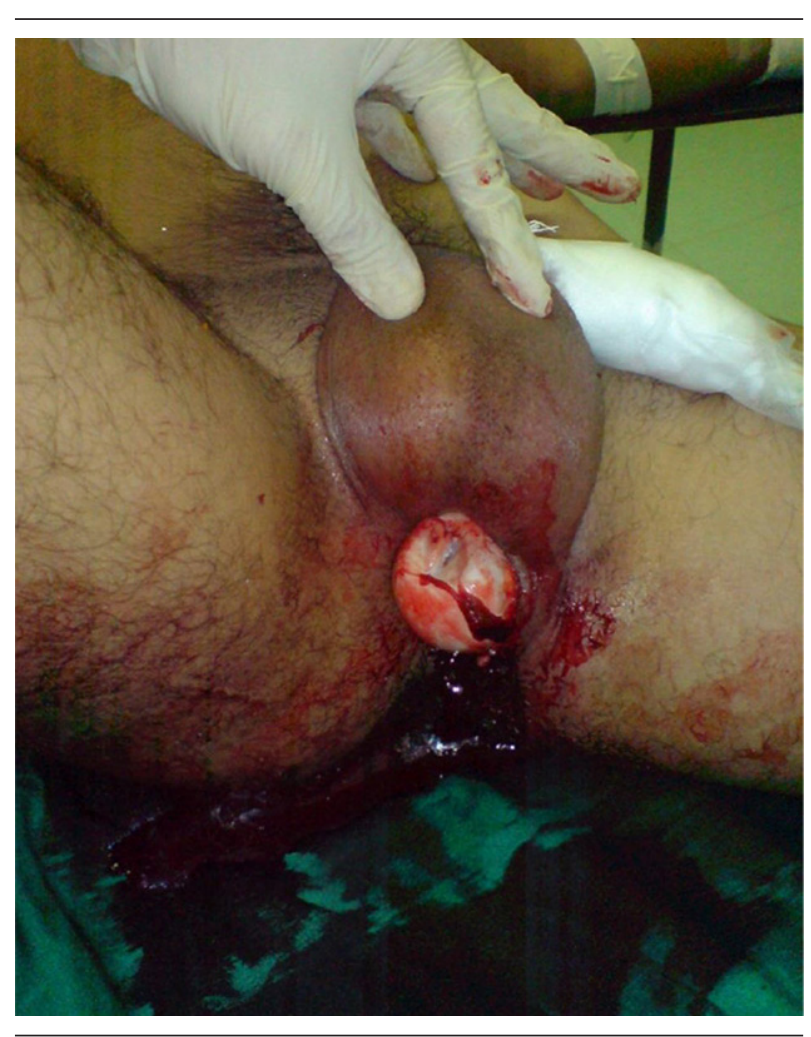

Figure 1. Preoperative Photography of Patient With Open Perineal Anterior Dislocation of the Left Hip

Copyright (C) 2015, Iran University of Medical Sciences. This is an open-access article distributed under the terms of the Creative Commons Attribution-NonCommercial 4.0 International License (http://creativecommons.org/licenses/by-nc/4.0/) which permits copy and redistribute the material just in noncommercial usages, provided the original work is properly cited. 


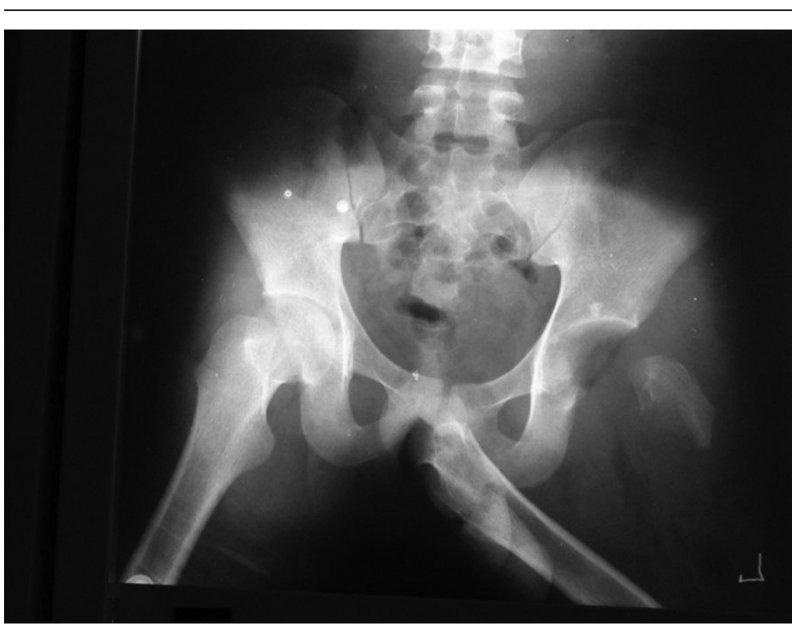

Figure 2. Anteroposterior X-Ray With Left Hip Perineal Anterior Dislocation
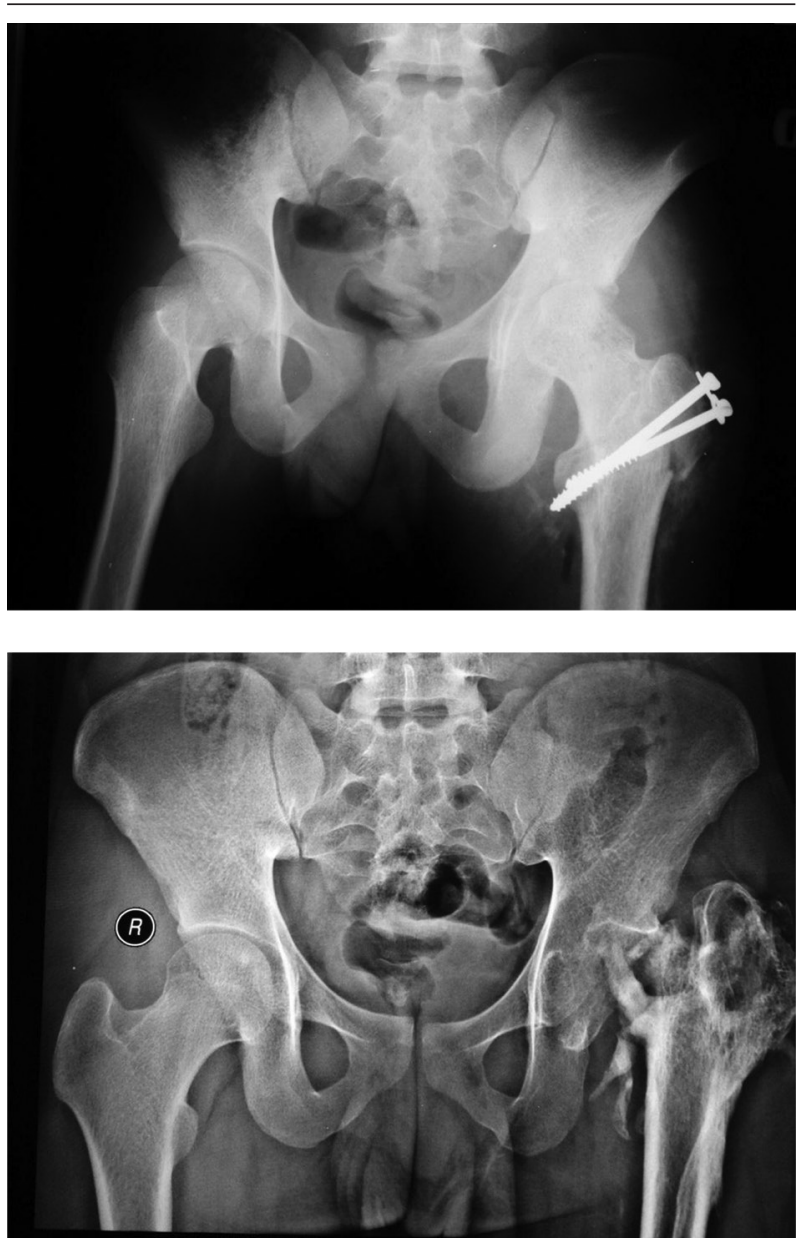

Figure 3. Anteroposterior Pelvic X-Ray After Fixation Of Greater Trochanter and X-ray of Pelvis 18 Months After Accident

In less than 3 hours from accident time, in coordination with the general surgeon, the patient was transferred to the operating room due to the open hip fracture disloca- tion and acute abdomen of splenic rupture. Femoral neck was lacking soft tissue attachment. The femoral head had multiple osteochondral fractures. Wound debrided and extended for irrigation. The femoral head reduced closely after exhaustive irrigation and debridement. Anal sphincter repair, laparotomy and splenectomy were done at the same time by general surgeon. Left lower limb pulses were not palpable and severe edema was present at the injured lower limb. Angiography revealed patent arteries in spite of absent distal pulses. The pulses were palpable 5 days later. One week later, after stabilization of patient's general condition, through a lateral incision open reduction and fixation of greater trochanter were done by two screws, we noticed that the hip joint capsule and retinaculum were damaged severely. Five days after operation, signs of infection appeared in lateral incision. In multiple sessions, irrigation and debridement of the necrotic tissues and excision of loosed femoral head fragments were done through the same approach, without hip dislocation. Discharge from incision continued to 3 months after operation. X-ray and magnetic resonance imaging (MRI) of hip revealed avascular necrosis and resorption of femoral head.

Eighteen months after dislocation, there was sever limitation of hip motion (flexion 70 degree, internal and external rotation 10 degree, abduction and adduction 10 degree, extension 10 degree), 4 centimeters shortening, sever limping with minor pain (Figure 3).

\section{Discussion}

In Epstein classification, depending on the position of the femoral head, anterior dislocations have been divided into two types, superior (pubic) and inferior (obturator) type (1). De-Lee et al. adds perineal dislocation to the low type of anterior dislocation, in which the head lies more inferior to the usual obturator type (2). Traumatic open anterior perineal hip dislocation, with associated fracture of femoral head and greater trochanter, is a rare entity and research in database revealed only 11 cases of this kind of injury reported in the literature (3-6).

High energy motor vehicle trauma is main cause of hip dislocation. Pringle was the initially proposed mechanism of anterior inferior (perineal) dislocation of the hip (7). It consists of forced abduction and external rotation of the flexed hip causing the femoral head to tear through anterior inferior capsule. Shear fracture of anterosuperior aspect of femoral head is the result of force produced between femoral head and anterior inferior acetabular margin during dislocation. In cases of anterior dislocation, with fracture of femoral head, the results were unfavorable. The patients with fracture had a worse prognosis than those with simple dislocations. Scham treated his case by cup arthroplasty, 9 weeks after injury (8). In addition to traumatic arthritis, other potential complications are avascular necrosis of the femoral head and myositis ossificans. In open anterior dislocation, neurovascular injury and infection are other serious complications (9). 
Jalili A et al.

\begin{tabular}{|c|c|c|c|c|}
\hline & Excellent & Good & Fair & Poor \\
\hline & All of the following & All of the following & $\begin{array}{l}\text { Any one or more of the } \\
\text { following }\end{array}$ & $\begin{array}{l}\text { Any one or more of the } \\
\text { following }\end{array}$ \\
\hline Pain & No pain & No pain & Pain but not disabling & Disabling pain \\
\hline Motion & Full range of hip motion & $\begin{array}{l}\text { Free motion ( } 75 \% \text { of } \\
\text { normal hip) }\end{array}$ & $\begin{array}{l}\text { Limited motion of the hip, } \\
\text { no adduction deformity }\end{array}$ & $\begin{array}{l}\text { Marked limitation of } \\
\text { motion or adduction } \\
\text { deformity }\end{array}$ \\
\hline Limp & No limp & No more than slight limp & Moderate limp & Redislocation \\
\hline Roentgenographic & $\begin{array}{l}\text { No roentgenographic evidence } \\
\text { of progressive changes }\end{array}$ & $\begin{array}{c}\text { Minimum } \\
\text { roentgenographic changes }\end{array}$ & $\begin{array}{l}\text { Moderately severe } \\
\text { roentgenographic changes }\end{array}$ & $\begin{array}{l}\text { Progressive roentgeno- } \\
\text { graphic changes }\end{array}$ \\
\hline
\end{tabular}

In closed anterior dislocation of the hip, the risk of avascular necrosis varies from 1.7 to $40 \%$ (10). This complication is more frequent in open dislocations (3-6). In 11 reported open anterior dislocation of the hip, there were five cases of avascular necrosis. Three cases of these five had concomitant infection. Schicho and Riepl reported a femoral head dislocation to the scrotum in a 33 year old man, recently (11). They treated the patient with open reduction and internal fixation and, after 14 months, the follow up of the femoral head was vital and without avascular necrosis (11).

Factors correlated to the poor prognosis are severity of injury (open dislocation), associated fractures and delayed reduction. In the case in which he had open perineal dislocation of the hip, poor prognosis could be due to infection and avascular necrosis, as a result of severe retinaculum injury during the primary trauma or numerous irrigations and debridements.

Epstein classified clinical results of patients after hip dislocation (1) (Table 1).

According to this classification, the functional result of our patient was poor; infection and avascular necrosis are the two main causes of our poor result. Contamination of femoral head in perineal region and severe injury to vascular supply of femoral head are its causes.

\section{Acknowledgements}

We thank Karen Shashok (Author AID in the Eastern
Mediterranean) for improving the use of English in the manuscript.

\section{References}

1. Epstein HC. Traumatic Dislocations of the Hip. Clin Orthop Relat Res. 1973;92:116-42.

2. De-Lee JC, Evans JA, Thomas J. Anterior dislocation of the hip and associated femoral-head fractures. J Bone Joint Surg. 1980;62(6):960-4.

3. De-Oliveira AL, Machado EG. Open anterior dislocation of the hip in an adult: a case report and review of literature. Rev Bras Ortop. 2014;49(1):94-7.

4. Tornetta P. Hip dislocations and fractures of the femoral head. In: Bucholz RW, Heckman JD, Court-Brown CM editors. Rockwood and Green's fractures in adults. 5th ed. Philadelphia: Lippincott Williams \& Wilkins. 6 ed. Philadephia: Lippincott, Williams and Wilkins; 2006. pp. 1716-52.

5. Muzaffar N, Ahmad N, Bhat A, Shah N. Open anterior hip fracture dislocation in a young adult with exposed femoral Head: A case report:: Webmed Cent Orthop; 2011. Available from: http://www. webmedcentral.com/article_view/2170.

6. Mata SG, Ovejero AH, Grande MM. Open anterior dislocation of the hip in a child. J Pediatr Orthop B. 1998;7(3):232-4.

7. Pringle JH, Edwards AH. Traumatic dislocation of the hip joint: an experimental study on the cadaver. Glasgow Med J.1943;21:25-40.

8. Scham SM, Fry LR. 15 Traumatic Anterior Dislocation of the Hip With Fracture of the Femoral Head: A Case Report. Clin Orthop Relat Res. 1969;62:133-5.

9. Schwartz DL, Haller JA. Open Anterior Hip Dislocation with Femoral Vessel Transection in a Child. J Trauma: Inj Infect Crit Care. 1974;14(12):1054-9.

10. Erb RE, Steele JR, Nance EPJ, Edwards JR. Traumatic anterior dislocation of the hip: spectrum of plain film and CT findings. AJR Am J Roentgenol.1995;165(5):1215-9.

11. Schicho A, Riepl C. Femoral-Head Dislocation to the Scrotum. New Engl J Med. 2015;372(9):863. 